\title{
Of faeces and sweat. How much a mouse is willing to run: having a hard time measuring spontaneous physical activity in different mouse sub-strains
}

\author{
Dario Coletti (1, 2, 3), Sergio Adamo (2, 3), Viviana Moresi (2,3)
}

(1) Sorbonne Universités, UPMC Univ Paris 06 (CNRS, UMR 8256, INSERM ERL U1164), Institut Biologie Paris-Seine, Paris, France; (2) Dept. of Anatomy, Histology, Forensic Medicine \& Orthopedics, School of Medicine Sapienza University of Rome, Italy; (3) Interuniversity Institute of Myology.

This article is distributed under the terms of the Creative Commons Attribution Noncommercial License (CC BY-NC 4.0) which permits any noncommercial use, distribution, and reproduction in any medium, provided the original author(s) and source are credited.

\begin{abstract}
Invited Letter to the Editor. Physical activity has multiple beneficial effects in the physiology and pathology of the organism. In particular, we and other groups have shown that running counteracts cancer cachexia in both humans and rodents. The latter are prone to exercise in wheel-equipped cages even at advanced stages of cachexia. However, when we wanted to replicate the experimental model routinely used at the University of Rome in a different laboratory (i.e. at Paris 6 University), we had to struggle with puzzling results due to unpredicted mouse behavior. Here we report the experience and offer the explanation underlying these apparently irreproducible results. The original data are currently used for teaching purposes in undergraduate student classes of biological sciences.

Key Words: BALB/c mice, murine sub-strains, inbred mouse strains, running behavior,
\end{abstract} endurance exercise

Eur J Transl Myol 2017;27(1):67-70

Spontaneous exercise increases the life span of tumorbearing mice ${ }^{1}$ by counteracting muscle wasting and tumor growth. ${ }^{2}$ In turn, neuromodulation counteracts muscle atrophy, proving that muscle homeostasis needs contraction. ${ }^{3}$ In order to investigate the mechanisms underlying these phenomena, our research group used a training protocol for mice carrying out spontaneous exercise. We wanted to replicate the experimental model originally used at the Sapienza University of Rome in a different laboratory at Paris 6 University. In the present paper we report the strange occurrence of not being able to replicate the experiment in other laboratories and we speculate that the small genetic differences in the inbred mice used in the two different laboratories can account for this discrepancy. The amount of exercise done was measured by a tachometer (like the ones usually employed on bikes, yielding data such as distance run, average speed etc.) placed in wheel-equipped cages, hosting a single mouse. We and other authors showed that mice run between 4 and $8 \mathrm{Km} / \mathrm{d}^{4,2}$ In order to analyze spontaneous physical activity in mice running on a wheel in the Paris laboratory, we ordered mice (female, BALB/c of the same age as those used in Rome) and tachometers (the same catalogue number and vendor than in Rome); we also purchased two kinds of wheels, slightly different from those in Rome: one was in blue plastic, with a continuous surface for running (closed wheel); the other was black, metallic and had a ladder for running (open wheel). Was it possible that the wheel type could affect mouse running behavior? - we asked ourselves. The measurements after the first 24 hours were encouraging on one hand - the two types of wheel made no difference - but on the other, depressing, since in both cases the mice ran for only $0.5 \mathrm{Km}$ - far less than expected (see exp. 1 on Jan 16; Table 1). On the following days the data indicated that the mice were not running at all (see exp. 1 on Jan 17; Table 1). We replaced the mice with others. The result was hopelessly invariable: less than $0.5 \mathrm{Km}$ of running per day, or no running at all (see exp. 2 on Jan 30; Table 1). Again, we could not measure any running activity on the second day of the experiment, in sharp contrast with the first day, when we observed scarce, but measurable running activity (exp. 2 on Jan 31; Table 1). Of course, one after the other, we excluded the variables which could affect mouse behavior: the room, the position of the cage in the room, the type of cage, the environmental enrichment (data not shown). But why were the French mice so lazy? 


\section{Of faeces and sweat}

Eur J Transl Myol 2017; 27 (1): 67-70

Table 1. Original data on mouse running recorded at the University Pierre et Marie Curie, Paris 6

\begin{tabular}{|c|c|c|c|c|c|c|c|c|c|c|c|}
\hline $\begin{array}{c}\text { exper } \\
\quad \#\end{array}$ & mouse \# & rec. date & $\begin{array}{l}\text { distance } \\
\mathrm{Km} \text { /day }\end{array}$ & $\begin{array}{l}\text { wheel } \\
\text { type }\end{array}$ & env. & $\begin{array}{l}\text { tacho- } \\
\text { meter }\end{array}$ & rec. date & $\begin{array}{l}\text { distance } \\
\mathrm{Km} \text { /day }\end{array}$ & $\begin{array}{l}\text { wheel } \\
\text { type }\end{array}$ & env. & $\begin{array}{l}\text { tacho- } \\
\text { meter }\end{array}$ \\
\hline 1 & 1 & Jan 16 & 2 & $\mathrm{C}$ & $\mathrm{AF}$ & $9 \mathrm{~W}$ & $\operatorname{Jan} 17$ & 0 & $\mathrm{C}$ & $\mathrm{AF}$ & $9 \mathrm{~W}$ \\
\hline 1 & 2 & Jan 16 & 0 & C & $\mathrm{AF}$ & $9 \mathrm{~W}$ & Jan 17 & 0 & C & $\mathrm{AF}$ & $9 \mathrm{~W}$ \\
\hline 1 & 3 & Jan 16 & 0 & $\mathrm{C}$ & $\mathrm{AF}$ & $9 \mathrm{~W}$ & Jan 17 & 0 & $\mathrm{C}$ & $\mathrm{AF}$ & $9 \mathrm{~W}$ \\
\hline 1 & 4 & Jan 16 & 0 & $\mathrm{C}$ & $\mathrm{AF}$ & $9 \mathrm{~W}$ & $\operatorname{Jan} 17$ & 0 & $\mathrm{C}$ & $\mathrm{AF}$ & $9 \mathrm{~W}$ \\
\hline 1 & 5 & Jan 16 & 0.1 & Op & $\mathrm{AF}$ & $9 \mathrm{~W}$ & Jan 17 & 0 & $\mathrm{Op}$ & $\mathrm{AF}$ & $9 \mathrm{~W}$ \\
\hline 1 & 6 & Jan 16 & 0 & $\mathrm{Op}$ & $\mathrm{AF}$ & $9 \mathrm{~W}$ & Jan 17 & 0 & $\mathrm{Op}$ & $\mathrm{AF}$ & $9 \mathrm{~W}$ \\
\hline 1 & 7 & Jan 16 & 0.5 & $\mathrm{Op}$ & $\overline{\mathrm{AF}}$ & $9 \mathrm{~W}$ & Jan 17 & 0 & $\mathrm{Op}$ & $\overline{\mathrm{AF}}$ & $9 W$ \\
\hline 1 & 8 & Jan 16 & 1 & Op & $\mathrm{AF}$ & $9 \mathrm{~W}$ & Jan 17 & 0 & Op & $\mathrm{AF}$ & $9 \mathrm{~W}$ \\
\hline 2 & 9 & Jan 30 & 0.1 & C & $\mathrm{AF}$ & $9 \mathrm{~W}$ & Jan 31 & 0 & C & $\mathrm{AF}$ & $9 \mathrm{~W}$ \\
\hline 2 & 10 & Jan 30 & 0 & $\mathrm{C}$ & $\mathrm{AF}$ & $9 W$ & Jan 31 & 0 & $\mathrm{C}$ & $\mathrm{AF}$ & $9 \mathrm{~W}$ \\
\hline 2 & 11 & Jan 30 & 1.5 & $\mathrm{C}$ & $\mathrm{AF}$ & $9 \mathrm{~W}$ & Jan 31 & 0 & $\mathrm{C}$ & $\mathrm{AF}$ & $9 \mathrm{~W}$ \\
\hline 2 & 12 & Jan 30 & 0 & $\mathrm{C}$ & $\mathrm{AF}$ & $9 W$ & Jan 31 & 0 & $\mathrm{C}$ & $\mathrm{AF}$ & $9 \mathrm{~W}$ \\
\hline 2 & 13 & Jan 30 & 0.9 & $\mathrm{Op}$ & $\mathrm{AF}$ & $9 \mathrm{~W}$ & Jan 31 & 0 & $\mathrm{Op}$ & $\mathrm{AF}$ & $9 \mathrm{~W}$ \\
\hline 2 & 14 & Jan 30 & 0 & $\mathrm{Op}$ & $\mathrm{AF}$ & $9 \mathrm{~W}$ & Jan 31 & 0 & Op & $\mathrm{AF}$ & $9 W$ \\
\hline 2 & 15 & Jan 30 & 0.5 & Op & $\mathrm{AF}$ & $9 \mathrm{~W}$ & Jan 31 & 0 & Op & $\mathrm{AF}$ & $9 \mathrm{~W}$ \\
\hline 2 & 16 & Jan 30 & 0 & $\mathrm{Op}$ & $\mathrm{AF}$ & $9 \mathrm{~W}$ & Jan 31 & 0 & $\mathrm{Op}$ & $\mathrm{AF}$ & $9 \mathrm{~W}$ \\
\hline 3 & 9 & Feb 8 & 0 & Op & $\mathrm{AF}$ & $9 \mathrm{~W}$ & Feb 10 & 2 & Op & LAB & $9 \mathrm{~W}$ \\
\hline 3 & 10 & Feb 8 & 0 & Op & $\mathrm{AF}$ & $9 \mathrm{~W}$ & Feb 10 & 0 & Op & LAB & $9 \mathrm{~W}$ \\
\hline 3 & 11 & Feb 8 & 0 & $\mathrm{Op}$ & $\mathrm{AF}$ & $9 \mathrm{~W}$ & Feb 10 & 0 & $\mathrm{Op}$ & LAB & $9 \mathrm{~W}$ \\
\hline 3 & 12 & Feb 8 & 0.1 & $\mathrm{Op}$ & $\mathrm{AF}$ & $9 \mathrm{~W}$ & Feb 10 & 0.1 & Op & LAB & $9 \mathrm{~W}$ \\
\hline 3 & 13 & Feb 8 & 2 & $\mathrm{Op}$ & $\mathrm{AF}$ & $7 \mathrm{C}$ & Feb 10 & 0.5 & $\mathrm{Op}$ & LAB & $7 \mathrm{C}$ \\
\hline 3 & 14 & Feb 8 & 0 & Op & $\mathrm{AF}$ & $7 \mathrm{C}$ & Feb 10 & 0 & Op & LAB & $7 \mathrm{C}$ \\
\hline 3 & 15 & Feb 8 & 0 & Op & $\mathrm{AF}$ & $7 \mathrm{C}$ & Feb 10 & 0 & Op & LAB & $7 \mathrm{C}$ \\
\hline 3 & 16 & Feb 8 & 0 & Op & $\mathrm{AF}$ & $7 \mathrm{C}$ & Feb 10 & 1.5 & $\mathrm{Op}$ & LAB & $7 \mathrm{C}$ \\
\hline
\end{tabular}

Female mice BALB/c J (aged 8 weeks), were ordered from Janvier and individually hosted in wheel equipped cages. Mice were numbered univocally (equal numbers in different experiments $=$ same animals) and their running activity recorded over the time shown. Abbreviations: experiment number (exp. \#); wheel type (open, Op; closed, C); environment (env.), either the animal facility (AF) or the laboratory (LAB); tachometer model: DC9-WiFi (9W), or DC7-cable (7C). Additional, average data are published elsewhere. ${ }^{4}$

Looking for external advice, we described the whole story to a colleague of Physiology. When showing him the two types of wheel we noticed a long streak of faeces stuck onto the internal surface of the closed wheel. The lumps were too numerous and regularly dropped - right in the middle of the wheel and along its whole circumference - to be the result of hazard. The mice had spent time on that wheel going all around it, defecating while running. On the contrary with the open wheel this phenomenon had not been observed, since the faeces had been dropped through the ladder onto the litter. So the mice ran but the tachometer measured no activity. By looking again at the data sheet, we realized the tachometer in Paris had, at the time, an energy saving mechanism switching to standby after 30 minutes of inactivity. Since the device was supposed to be installed on a bike and turned on again by the biker at any new ride, the mice, apparently, had just jumped on 


\section{Of faeces and sweat}

Table 2. Comparison of the running behavior of different sub-strains of the BALB/c mice

\begin{tabular}{|c|c|c|c|c|}
\hline $\begin{array}{c}\text { experime } \\
\text { nt \# }\end{array}$ & mouse \# & $\begin{array}{l}\text { rec. date } \\
\text { (from - to) }\end{array}$ & $\begin{array}{c}\text { average } \\
\text { distance } \\
(\mathrm{Km} / \text { day })\end{array}$ & $\begin{array}{l}\text { sub- } \\
\text { strain }\end{array}$ \\
\hline 4 & 17 & March 26-30 & 6.6 & $\mathrm{AnNCrl}$ \\
\hline 4 & 18 & March 26-30 & 3.9 & AnNCrl \\
\hline 4 & 19 & March 26-30 & 4.0 & $\mathrm{AnNCrl}$ \\
\hline 4 & 20 & March 26-30 & 4.1 & $\mathrm{AnNCrl}$ \\
\hline 4 & 21 & March 26-30 & 7.1 & AnNCrl \\
\hline 4 & 22 & March 26-30 & 4.8 & $\mathrm{AnNCrl}$ \\
\hline 4 & 23 & March 19-23 & 5.7 & ByJ \\
\hline 4 & 24 & March 19-23 & 5.0 & ByJ \\
\hline 4 & 25 & March 19-23 & 1.2 & ByJ \\
\hline 4 & 26 & March 19-23 & 3.0 & ВyJ \\
\hline 4 & 27 & March 19-23 & 5.6 & ByJ \\
\hline 4 & 28 & March 19-23 & 7.0 & ByJ \\
\hline 4 & 29 & April 2-6 & 5.9 & $\mathrm{~J}$ \\
\hline 4 & 30 & April 2-6 & 1.8 & $\mathrm{~J}$ \\
\hline 4 & 31 & April 2-6 & 4.2 & $\mathrm{~J}$ \\
\hline 4 & 32 & April 2-6 & 3.0 & $\mathrm{~J}$ \\
\hline 4 & 33 & April 2-6 & 3.4 & $\mathrm{~J}$ \\
\hline 4 & 34 & April 2-6 & 3.7 & $\mathrm{~J}$ \\
\hline
\end{tabular}

Female mice BALB/c of different sub-strains as indicated (aged 8 weeks) were ordered from Janvier. The mice were individually hosted in open wheel equipped cages and their running activity recorded by a DC7 tachometer over the time shown (the average $\mathrm{Km}$ run per day are reported). All the animals were hosted in the animal facility. Mice were numbered univocally and the running distance for each animal is reported (data from runners only). Additional, average data are published elsewhere. ${ }^{4}$

the wheel and started running while the tachometer was simply still off.

We thought this was the happy end of a very didactic story. We purchased an older, more primitive tachometer model, which allowed intermittent recordings by remaining always on, and we started the experiments all over again. We recorded mouse activity, but most of the mice still did not run and even the runners were doing just a couple of Km/day (see exp. 3 on Feb 8; Table 1). After a couple of days, we again tested the recording capacity of the tachometers; in addition, we tested the environment too, moving the cages from the animal facility to the laboratory (and making sure to restart the tachometer when needed, see exp. 3 on Feb 10; Table 1). The previous results were confirmed.

The vendor of the mice we were using in Paris was different from the vendor we had in Rome. Even though BALB/c (the "Bagg albino") mice are an inbred strain and should be nearly identical the one to the other in genotype, we started hypothesizing that differences could exists between the two BALB/c mouse colonies purchased in the two countries. What came out is that the vendor in Rome sells a sub-strain called BALB/c AnNCrl (from: Andervont in 1935, to NIH in 1951 from Andervont at F72, to Charles River in 1974 from NIH), while the Paris vendor sells either the sub-strain we were using, BALB/c J (from: redonated back to Jackson Laboratory by J. Paul Scott in 1947) or the BALB/c ByJ (from: donated to Jackson labs by Bailey J in 1974).

When comparing the running behavior of the three substrains we obtained striking results (Table 2). While 94\% of the AnNCrl mice ran, when hosted in a wheel equipped cage, only $72 \%$ and $38 \%$ of runners were observed for the ByJ and $\mathrm{J}$ sub-strains, respectively. These figures remained constant and were statistically confirmed. In addition, AnNCrl runners covered at least $5 \mathrm{Km} / \mathrm{d}$, while the lazier $\mathbf{J}$ mice, even when willing to run, covered only $3.7 \mathrm{Km} / \mathrm{d}$. Detailed quantitative data on these observations were recently published. ${ }^{4,5}$ The raw data reported in Table 1 and 2 can be useful for classes, in which guided observations and data interpretation and analysis can be supported by a simulation of real laboratory experiences.

Based on our findings, the probability that a mouse may perform spontaneous exercise, such as wheel running, depends on its specific sub-strain. Data on mouse running behavior are available from the Jackson Laboratories ${ }^{6}$ and further figures on differences among strains and sub-strains have also been published. ${ }^{7-9}$ We find it quite surprising that such a significant difference exists in mouse behavior, when comparing different sub-strains of the same inbred strain. Nonetheless, we think that fine genetic differences among the three $\mathrm{BALB} / \mathrm{c}$ sub-strains are the most likely explanation underlying this phenomenon. Genetic mutations and, more likely, a genetic drift could have occurred in relatively small mouse populations which were isolated in different countries over a period of over 80 years. As a matter of fact, inbred strains evolve very quickly and show elevated genetic divergence, with the distribution of alleles among them being neither simple nor random. ${ }^{10}$ The reasons for such diversity are discussed in a brilliant editorial by Lewin. ${ }^{11}$ In addition, physical activity elicits adaptive responses ${ }^{12}$ and geneenvironment interactions may affect adaptive capacities as typically seen in inbred strains. ${ }^{13,14}$

In conclusion, diversity among inbred mouse sub-strains significantly affects the choice a mouse sub-strain for experimental procedures, especially when they involve 


\section{Of faeces and sweat}

Eur J Transl Myol 2017; 27 (1): 67-70

exercise training. It also has economic fallouts: depending on which sub-strain is used there is a significant risk of wasting resources. Different substrains have different prices, so the delicate choice of a given sub-strain should be made after a careful calculation of costs vs benefits taking into account that, in order to have runner mice, a laboratory must order the right sub-strain even if the mice are all inbred $\mathrm{BALB} / \mathrm{c}$. We believe that the scientific community would benefit from additional studies on inbred mouse behavior and feel that some contradictory findings may be explained by a detailed analysis of the differences in the animal model used.

\section{Author's contributions}

DC wrote the manuscript and performed data analysis; SA wrote the manuscript and coordinated the experimental work.; VM wrote the manuscript and contributed to data analysis.

\section{Acknowledgments}

We gratefully thank Anna Luisa Mazzotti for reviewing the English in the manuscript. DC is funded by AFM (2012-0773), ANR (2013-J13R191), EFEM 2016, IBPS (2014), NIH (2013-1R01CA108857-01 subcontractor) and UPMC Emergence (2011-EME1115). SA is funded by MIUR, 2012 PRIN grant 2012N8YJC3-002.

\section{Conflict of Interest}

The authors declare no conflicts of interest.

\section{Corresponding Author}

Prof. Dario Coletti

Institute of Biology Paris-Seine, B2A Biological Adaptation and Ageing (CNRS UMR 8256 - INSERM ERL U1164 - UPMC P6), University Pierre et Marie Curie Paris 6, 7, quai St Bernard, bat A, 6eme étage, case courrier 256, 75252 Paris Cedex 5 France tel. +33 (0) 144273475 - fax. +33 (0) 144272135

Email dario.coletti@upmc.fr

\section{E-mails of coAuthors}

Sergio Adamo: sergio.adamo@uniroma1.it Viviana Moresi: viviana.moresi@uniroma1.it

\section{References}

1. Pigna E, Berardi E, Aulino P, et al. Aerobic Exercise and Pharmacological Treatments
Counteract Cachexia by Modulating Autophagy in Colon Cancer. Sci Rep 2016 May 31;6:26991.

2. Hiroux C, Vandoorne T, Koppo K, et al. Physical activity counteracts tumor cell growth in colon carcinoma C26-injected muscles: an interim report Eur J Transl Myol 2016;26:5958.

3. Carraro U, Coletti D, Kern H. The Ejtm Specials "The Long-Term Denervated Muscle". Eur J Transl Myol. 2014;24:3292.

4. Coletti D, Berardi E, Aulino P, et al. Substrains of inbred mice differ in their physical activity as a behavior. Scientific World Journal. 2013;2013:237260.

5. Coletti D, Aulino P, Pigna E, et al. Spontaneous physical activity downregulates Pax7 in cachexia. Stem Cells Int 2016;2016:6729268.

6. The Jackson Laboratory, Bar Harbor, Maine USA. Mouse Phenome Database http://phenome.jax.org [Cited 13 Dec, 2016]

7. Knab AM, Bowen RS, Moore-Harrison T, et al. Repeatability of exercise behaviors in mice. Physiol Behav 2009;98:433-40.

8. Girard I, McAleer MW, Rhodes JS, et al. Selection for high voluntary wheel-running increases speed and intermittency in house mice (Mus domesticus). J Exp Biol 2001;204(Pt 24):4311-20.

9. Lightfoot JT, Leamy L, Pomp D, et al. Strain screen and haplotype association mapping of wheel running in inbred mouse strains. J Appl Physiol. 2010;109(3):623-34.

10. Hickman-Davis JM. Implications of mouse genotype for phenotype. News Physiol Sci 2001;16:19-22.

11. Lewin R. Why do inbred mice evolve so quickly? Science. Why do inbred mice evolve so quickly? Science 1985;228:1187.

12. Baldwin KM, Klinkerfuss GH, Terjung RL, et al. Respiratory capacity of white, red, and intermediate muscle: adaptative response to exercise. Am J Physiol 1972;222:373-8.

13. Boleij H, Salomons AR, van Sprundel M, et al. Not all mice are equal: welfare implications of behavioural habituation profiles in four 129 mouse substrains. PLoS One 2012;7(8):e42544.

14. Bothe GWM, Bolivar VJ, Vedder MJ, Geistfeld JG. Behavioral differences among fourteen inbred mouse strains commonly used as disease models. Comp Med 2005;55: 326-34. 